\title{
Pengaruh Abdominal Streaching Excercise Dalam Menurunkan Kejadian Dysmenorrea pada Remaja Putri
}

\author{
Penulis: \\ Catur Yulinawati ${ }^{1}$ \\ Mona Rahayu Putri
}

\begin{abstract}
Afiliasi :
Institut Kesehatan Mitra

Bunda
\end{abstract}

Korespondensi:

putrimonarahayu@gmail

.$c o m$

Histori Naskah:

Diajukan: 2022-01-18

Disetujui: 2022-01-19

Publikasi: 2022-01-21

\begin{abstract}
Abstrak:
Dysmenorrea adalah masalah kesehatan reproduksi berupa gangguan fisik pada seorang wanita yang sedang mengalami menstruasi, gangguan tersebut adanya rasa nyeri atau kram pada bagian perut bawah yang menjalar sampai dengan punggung. Dysmenorrea merupakan ketidaknyamanan yang sering terjadi pada remaja putri sehingga dapat mengganggu konsenterasi belajar. Latihan latihan berupa peregangan terutama pada daerah perut dapat mengurangi rasa nyeri pada saat menstruasi. Tujuan penelitian ini adalah untuk menganalisis pengaruh latihan peregangan pada perut dalam menurunkan dysmenorrea atau rasa nyeri menstruasi pada remaja putri. Metode penelitain ini adalah quasy exsperimen dengan desain non equivalent control grup design. Populasi pada penelitian ini adalah remaja putri yang berusia 12 tahun sampai dengan 15 tahun berjumlah 38 orang yaitu 19 orang untuk masing masing kelompok kontrol dan perlakuan. Teknik pengambilan sampel penelitian ini menggunakan purposive sampling. Analisis data menggunakan uji MannWhitney. Perlakuan dilakukan sebanyak 3 kali seminggu selama 8 minggu. Hasil penelitian menunjukan p-value $=0.043$ sehingga $<\alpha(0.05)$ bahwa latihan peregangan perut pada remaja putri dapat membantu mengurangi dysmenorrea atau rasa nyeri menstruasi. Dysmenorrea atau nyeri perut bawah pada saat menstruasi dapat dikurangi dengan non farmakologi yaitu dengan melakukan latihan peregangan perut atau abdominal streaching excercise
\end{abstract}

Kata kunci: Dysmenorrea, Abdominal Streaching Excercice, Remaja Putri

\section{Pendahuluan}

Remaja merupakan suatu peralihan dari masa anak-anak ke masa dewasa. Masa remaja adalah usia 10-19 tahun, ditandai dengan munculnya karakteristik seks primer, hal tersebut dipengaruhi oleh mulai bekerjanya kelenjar reproduksi. Pada wanita pubertas ditandai dengan terjadinya haid. Haid adalah luruhnya sel ovum yang tidak dibuahi, usia normal wanita mengalami haid untuk pertama kalinya pada usia 12 atau 13 tahun yang disebut menarche. Menarche merupakan pertanda berakhirnya masa pubertas, masa peralihan dari masa anak-anak menuju dewasa. Haid yang dialami para wanita remaja dapat menimbulkan masalah seperti polimenore $10,5 \%$, oligomenore $25 \%$, amenore $23,7 \%$, dan paling sering terjadi pada remaja yaitu dismenore $40,8 \%$. Dismenore merupakan masalah kesehatan reproduksi yaitu nyeri pada perut bagian bawah muncul sebelum, selama, dan segera setelah haid (Ernawati, 2018).

Menurut World Health Organization (WHO) dalam penelitian Nur A (2018). Angka kejadian dismenore cukup tinggi diseluruh dunia. Rata-rata insidensi terjadinya dismenore pada remaja putri antara 16,8-81\%. Rata-rata dinegara-negara Eropa dismenore terjadi sebesar $45-97 \%$ pada remaja putri. Dengan prevalensi terendah di Bulgaria $(8,8 \%)$ dan tertinggi mencapai $94 \%$ dinegara Finlandia. Sedangkan di Amerika Serikat, diperkirakan wanita yang mengalami dismenore hampir 90\%, dimana 10-15\% diantaranya mengalami dismenore berat yang menyebabkan remaja putri tidak mampu melakukan kegiatan apapun. Sementara data dismenore remaja di Indonesia sebesar 69,167 jiwa $(64,25 \%)$ yang terdiri dari 59,671 jiwa (54,89\%) mengalami dismenore primer dan 9,496 jiwa 
(9,36\%) mengalami dismenore sekunder. Walaupun pada umumnya tidak berbahaya namun sering kali dirasa menganggu bagi wanita yang mengalaminya (Nur A, 2018)

Laporan dari sesi kesehatan keluarga dan gizi Dinas Kesehatan Kota Batam, pada pelayanan kesehatan reproduksi peduli remaja (PKPR), didapatkan jumlah sasaran remaja dari 19 puskesmas yang paling banyak terdapat di Puskesmas Batu Aji 13.853 remaja putri, Puskesmas Sei Langkai 12.384 remaja putri, Puskesmas Baloi Permai 11.211 remaja putri. (Dinas Kesehatan Kota Batam, 2020)

Data yang didapatkan dari studi pendahuluan yang dilakukan terhadap remaja putri di SMP diperoleh jumlah kasus dismenore tertinggi di SMPN 35 Batam sebesar 68\%, Sekolah Tunas Muda Berkarya sebesar 64\%, SMPN 21 Batam sebesar 43\% dan Sekolah Pelita Bangsa sebesar 38\%. Penanganan dismenore pada remaja putri di SMPN 35 Batam yaitu minum obat 45\%, kompres hangat 10\%, dibiarin/dibawa tidur $10 \%$.

Penyebab dismenore adalah terjadinya kontraksi yang kuat atau lama pada dinding rahim, hormone prostaglandin yang cenderung tinggi, pelebaran leher rahim serta kontraksi myometrium yang terlalu kuat saat mengeluarkan darah haid. Sel-sel epitel, stoma, serta cairan dan lendir dari dinding uterus, sehingga menyebabkan ketegangan otot-otot saat berkontraksi dan terjadilah nyeri saat menstruasi (Nadjib Bustan et al., 2018)

Penatalaksanaan untuk mengurangi rasa nyeri saat haid (dismenorea) yaitu ada dua macam yang pertama farmakologi, pemberian obat anti-inflamasi nonstreroid (OAINS). Upaya farmakologi yang dapat dilakukan dengan memberikan obat analgesic sebagai penghilang rasa nyeri atau sakit. Obatobatan ini dapat menurunkan nyeri dan menghambat produksi prostaglandin dari jaringan-jaringan yang mengalami trauma dan inflamasi yang menghambat reseptor nyeri untuk menjadi sensitive terhadap stimulus menyakitkan sebelumnya. Kedua non farmakologi yaitu pola hidup sehat seperti hindari stress, istirahat yang cukup, menghindari makanan yang mengandung kadar garam tinggi dan kafein, olahraga/abdominal stretching exercise, kompres air hangat, mandi air hangat, akupuntur, akupresur, yoga, dan terapi musik (Burnett \& Lemyre, 2017)

Manajemen tanpa minum obat lebih aman digunakan selain sederhana, mudah dilakukan, tidak menimbulkan efek samping, dan tidak memerlukan biaya. Beberapa cara untuk meredakan dismenore dan keefektifannya yaitu kompres hangat 16,7\%, olahraga (abdominal stretching exercise) 19,1\%, istirahat cukup $15 \%$, diet rendah garam $12,4 \%$, akupuntur $11,4 \%$, akupresur $9,7 \%$, yoga $16 \%$, dan minum jamu/herbal $(18,8)$ (Wahyuni, A., 2016); Novita Sari et al, 2017)

Abdominal streaching excercise yang merupakan bagian dari olahraga dan pilihan yang tepat dengan melakukan latihan perengangan dan penguatan otot terutama pada bagian perut dan punggung bawah yang dilakukan selama 10-60 menit dan setidaknya 3 kali dalam seminggu selama 8 minggu. Latihan ini telah dirancang khusus untuk meningkatkan kekuatan otot, daya tahan dan fleksibilitas, sehingga diharapkan dapat mengurang nyeri haid. Senam aerobik ungtuk mengatasi dismenore terdiri dari enam gerakan yaitu cat stretch, lower trunk rotation, buttock / hip stretch, abdominal strengthening (curl up), lower abdominal strengthening dan the bridge position. Abdominal streaching excercise untuk mengurangi rasa nyeri atau dysmenorre melalui mekanisme yaitu dengan melakukan relaksasi otototot yang mengalami spasme yang disebabkan oleh peningkatan prostaglandin sehingga terjadi vasodilatasi pembuluh darah dan akan meningkatkan aliran darah ke daerah yang mengalami spasme dan iskemik. Selain itu, pada saat melakukan exercise senam aerobik, tubuh akan mengeluarkan opoid endogen yaitu endorphin dan enkefalin yang dihasilkan di otak dan sumsum tulang belakang. Zat-zat tersebut memiliki sifat mirip morfin dengan efek analgetik yang membentuk suatu sistem penekan nyeri (Dehghanzadeh et al., 2014; Nadjib Bustan et al., 2018). 


\section{Studi Literatur}

1. Konsep Remaja

Remaja atau adolescene berasal dari bahasa latin "adolescane" yang berarti tumbuh kearah kematangan. Kematangan yang dimaksud adalah bukan kematangan fisik saja tetapi juga kematangan social dan psikologi (Kumalasari dan Andhyantoro, 2013).

2. Konsep Dismenore

Dismenore adalah nyeri saat haid yang terasa diperut bagian bawah dan muncul sebelum, selama atau setelah menstruasi. Nyeri dapat bersifat kolik atau terus menerus. Dismenore timbul akibat kontraksi distritmik lapisan miometrium yang menampilkan satu atau lebih gejala mulai dari nyeri ringan sampai berat (Armour et al., 2019)

3. Senam

Olahraga/senam merupakan salah satu teknik relaksasi yang dapat digunakan untuk mengurangi nyeri karenasaat melakukan olahraga/senam, otak dan susunan saraf tulang belakang akan menghasilkan endorphin, hormone yang berfungsi sebagai obat penenang alami dan menimbulkan rasa nyaman (Kannan et al., 2019; Kannan \& Claydon, 2014)

\section{Metode Penelitian}

Jenis penelitian ini adalah Experimental berupa quasi experiment design dengan rancangan non equivalent control group. Rancangan non equivalent control group adalah rancangan penelitian yang digunakan untuk membandingkan hasil intervensi program kesehatan dengan kelompok kontrol yang serupa tetapi tidak perlu kelompok yang benar-benar sama. Kelompok kontrol yang dimaksud adalah suatu kelompok yang tidak dikenai perlakuan atau percobaan.

\section{Hasil}

\section{Analisis Univariat}

Analisa Univariat untuk mengetahui gambaran subjek penelitian dan variabel - variabel penelitian

Tabel 1

Karakteristik responden berdasarkan usia

\begin{tabular}{ccc}
\hline Usia & n & \% \\
\hline $\begin{array}{c}\text { Remaja Putri 12 -13 tahun } \\
\text { Remaja Putri } \\
\text { 14-15 tahun }\end{array}$ & 28 & $56 \%$ \\
\hline Total & 22 & $44 \%$ \\
\hline
\end{tabular}

Data penelitian berdasarkan usia remaja putri yang mengalami dysmenorrea yaitu usia 12-13 tahun terdapat 28 orang (56\%) dan usia 15-15 tahun terdapat 22 orang (44\%).

Tabel 2

Gambaran tingkat nyeri sebelum dan sesudah melakukan Latihan peregangan Perut

\begin{tabular}{ccccc}
\hline Variabel & \multicolumn{2}{c}{ Sebelum } & \multicolumn{2}{c}{ Sesudah } \\
\hline Dysmenorea & Frekuensi & $\%$ & Frekuensi & $\%$ \\
\hline Derajat 0 & 0 & 0 & 8 & 42,1
\end{tabular}


Volume: 1 | Nomor 1 | Januari 2022 | E-ISSN: 2809-911X |

DOI: doi.org/healthcaring.v1n1.1336

\begin{tabular}{ccccc} 
Derajat 1 & 5 & 26,3 & 9 & 47,3 \\
Derajat 2 & 5 & 26,3 & 1 & 5,3 \\
Derajat 3 & 8 & 42,1 & 1 & 5,3 \\
Derajat 4 & 1 & 5,3 & 0 & 0 \\
\hline Jumlah & 19 & 100 & 30 & 100 \\
\hline
\end{tabular}

Berdasarkan tabel 2 maka dapat diketahui bahwa tingkat dysmenorrea pada kelompok perlakuan sebelum diberikan perlakuan adalah sebgian besar mengalami derajat 3 sebanyak 8 orang $(42,1 \%)$ dan tingkat dysmenorrea setelah dilakukan perlakuan yaitu derajat 1 sebanyak 9 orang sebesar $47,3 \%$.

\section{Analisis Bivariat}

Tabel 3

Perbedaan Dysmenorrea sebelum dan Sesudah dilakukan Abdominal Streaching Excercise

\begin{tabular}{llllll}
\hline Variabel & Perlakuan & N & Mean & SD & Pvalue \\
\cline { 1 - 4 } Dysmenorrea & Sebelum & 19 & 2,16 & 0,744 & 0,000 \\
\cline { 1 - 4 } & Sesudah & 19 & 1.09 & 0,798 & \\
\hline
\end{tabular}

Berdasarkan tabel 3 dapat diketahui bahwa sebelum dilakukan latihan peregangan pada perut mean 2,16 dan setelah dilakukan perlakuan yang dilakukan selama 3 kali dalam seminggu selama 8 minggu yaitu 1,09 dan dapat telihat terdapat penurunan tingkat dysmenorrea.

Uji data menggunakan uji Wilcoxon yaitu p-value $0,000<\alpha \quad(0,05)$, maka Ho ditolak, terdapat perbedaan sebelum dan sesudah dilakukan latihan peregangan perut pada remaja putri.

Tabel 4

\begin{tabular}{llllll}
\hline Variabel & Post-test & $\mathrm{n}$ & Mean & SD & Pvalue \\
\cline { 1 - 4 } Dysmenorrea & Perlakuan & 19 & 1,09 & 0,799 & \multirow{2}{*}{0,040} \\
\cline { 1 - 4 } & Kontrol & 19 & 1.82 & 0,776 & \\
\hline
\end{tabular}

Berdasarkan tabel 5 bahwa terdapat perbedaan mean antara kelompok perlakuan yaitu 1,09 dan kelompok kontrol 1,82. p-value 0,040 < 0,05 sehingga disimpulkan terdapat pengaruh latihan peregangan perut dalam mengurangi rasa nyeri atau dysmenorrea pada remaja putri.

\section{Pembahasan}

Hasil penelitian pada tabel 4 bahwa terdapat perbedaan mean antara kelompok perlakuan yaitu 1,09 dan kelompok kontrol 1,82. p-value 0,040 < 0,05 sehingga disimpulkan ada pengaruh latihan peregangan perut dalam mengurangi rasa nyeri atau dysmenorrea pada remaja putri yang dilakukan 3 kali dalam seminggu selama 8 minggu.

Dismenore adalah nyeri saat haid yang terasa diperut bagian bawah dan muncul sebelum, selama atau setelah menstruasi. Nyeri dapat bersifat kolik atau terus menerus. Dismenore timbul akibat kontraksi distritmik lapisan miometrium yang menampilkan satu atau lebih gejala mulai dari nyeri ringan sampai berat (Nadjib Bustan et al., 2018) 
Latihan peregangan pada perut merupakan bagian dari olahraga yang dilakukan dengan melakukan latihan fisik sebagai salah satu cara mengurangi rasa nyeri secara non farmakologis yang menghasilkan hormon penenang alami, yaitu hormon endorphin. Olahraga juga dapat meningkatkan 4-5 kali hormon tersebut. Nyeri haid atau dysmenorrea terjadi akibat lapisan uterus yaitu endometrium mengalami peningkatan prostaglandin. Dibawah pengaruh hormon progesterone selama fase luteal haid, prostaglandin meningkat mencapai tingkat maksimum pada awal haid. Prostaglandin menyebabkan kontraksi myometrium yang kuat dan mampu menyempitkan pembuluh darah mengakibatkan iskemia, disentegrasi endometrium dan nyeri (Armour et al., 2019) .

Abdominal stretching exercise dilakukan $3 \mathrm{x}$ dalam seminggu selama 15-30 menit. Untuk remaja yang memiliki siklus menstruasi normal (28-30 hari) dapat melakukan abdominal stretching exercise dimulai saat mentruasi hari pertama sampai hari ketiga, dan untuk remaja yang memiliki siklus menstruasi yang tidak normal maka dapat dilakukan minggu ke-3 setelah menstruasi sebelumnya sebanyak 4-5 kali seminggu selama 8 minggu (Dehghanzadeh et al., 2014; Hailemeskel et al., 2016)

Hal ini didukung oleh penelitian M.Nadjib Bustan $d k k$ tahun 2018 yang berjudul "Latihan Peregangan Perut dalam Menurunkan Nyeri Dysmenorrea pada Mahasiswa Keperawatan" menunjukkan ada nya perbedaan bermakna nilai nyeri yaitu pada kelompok perlakuan 1,85 dan pada kelompok kontrol adalah 0,16 dengan p-value 0,000 sedangkan pada kelompok kontrol tidak ada perbedaan rerata instensitas nyeri baik sebelum dan sesudah intervensi.

\section{Kesimpulan}

Berdasarkan hasil penelitian tersebut bahwa melakukan latihan perengangan pada perut atau abdominal streaching excercise secara rutin sebanyak 3 kali dalam seminggu selama 8 minggu dapat menurunkan rasa nyeri menstruasi atau dysmenorrea pada remaja putri.

\section{Referensi}

Armour, M., Parry, K., Al-Dabbas, M. A., Curry, C., Holmes, K., MacMillan, F., Ferfolja, T., \& Smith, C. A. (2019). Self-care strategies and sources of knowledge on menstruation in 12,526 young women with dysmenorrhea: A systematic review and meta-analysis. PLoS ONE, 14(7), 1-18. https://doi.org/10.1371/journal.pone.0220103

Burnett, M., \& Lemyre, M. (2017). No. 345-Primary Dysmenorrhea Consensus Guideline. Journal of $\begin{array}{llll}\text { Obstetrics and } \text { Gynaecology } & \text { 39(7), 585-595. }\end{array}$ https://doi.org/10.1016/j.jogc.2016.12.023

Dehghanzadeh, N., Khoshnam, E., \& Nikseresht, A. (2014). The effect of 8 weeks of aerobic training on primary dysmenorrhea. Pelagia Research Library European Journal of Experimental Biology, 4(1), 380-382. www.pelagiaresearchlibrary.com

Hailemeskel, S., Demissie, A., \& Assefa, N. (2016). Primary dysmenorrhea magnitude, associated risk factors, and its effect on academic performance: Evidence from female university students in Ethiopia. International Journal of Women's Health, 8(September 2021), 489-496. https://doi.org/10.2147/IJWH.S112768

Kannan, P., Cheung, K. K., \& Lau, B. W. M. (2019). Does aerobic exercise induced-analgesia occur through hormone and inflammatory cytokine-mediated mechanisms in primary dysmenorrhea? Medical Hypotheses, 123(August 2018), 50-54. https://doi.org/10.1016/j.mehy.2018.12.011

Kannan, P., \& Claydon, L. S. (2014). Some physiotherapy treatments may relieve menstrual pain in 
Volume: 1 | Nomor 1 | Januari 2022 | E-ISSN: 2809-911X |

DOI: doi.org/healthcaring.v1n1.1336

women with primary dysmenorrhea: A systematic review. Journal of Physiotherapy, 60(1), 1321. https://doi.org/10.1016/j.jphys.2013.12.003

Nadjib Bustan, M., Seweng, A., \& Ernawati. (2018). Abdominal Stretching Exercise in Decreasing Pain of Dysmenorrhea among Nursing Students. Journal of Physics: Conference Series, 1028(1). https://doi.org/10.1088/1742-6596/1028/1/012103

Wahyuni, A., M. (2016). the Effect of Pilates Exercise To Hamper Primary Dysmenorrhea in 18-21 Years Old Adolescents. International Conference on Health and Well-Being, October, 413-417. https://publikasiilmiah.ums.ac.id/handle/11617/7431 